\title{
Environmental policy still undefined
}

The British Government, which has several problems on its mind, does not need new environmental legislation. Its Secretary of State for the Environment has probably ensured that the embarrassment can be postponed.

Poor Mr Christopher Patten, British Secretary of State for the Environment and the darling of British environmental lobbyists since his speech at the government party's conference a year ago, has unjustly been given a bad press for last week's white paper on environmental policy (see page 412). More accurately, he has been given a bad press for the wrong reasons. Patten's fickle lobbyist friends, as ever zealous in their pursuit of their ideal and tightly regulated world, are demanding to know why he has not committed the British government to such measures as the carbon tax they have been pushing at him for the past year, forgetting that Mr Saddam Hussein may have done that instead.

The more serious complaint, quite buried in the chorus of mistaken umbrage, is that the white paper fails to provide a framework within which this or any future British government can determine environmental policy in a coherent fashion. For a document subtitled "Britain's Environmental Strategy" (the title proper, This Common Inheritance, is taken from Stuart Mill), that is at best an oversight.

The principles, sadly, are not principles at all, but platitudes (yet nicely written). Almost the most daring statement in the document, but one that may sufficiently explain the disaffection of the lobbyists from Patten's way of seeing things, is that economic growth is taken to engender popular concern for environmental protection. Or, to be fair both to Patten and the lobbyists, as "people have enjoyed the benefits of economic growth, they have become increasingly preoccupied with the quality of their daily lives". From there, it is but a short step, by way of uplifting but cramping illustrative examples ("aspirations" for healthier living, "desire" for cleaner air, "enthusiasm" for protecting the best of "our" surroundings, "hope" that we can pass on the best of what we value most to our children), to a thoroughly middle-class view of the environmental problem.

What about the fellow (man or woman) who has it in his head that the benefits of economic growth are most aptly typified by the speed at which an affordable motorcar will travel from A to B? Or the others who will not cross the Atlantic except supersonically? Will aspirations to "healthier living" and the rest win them away from their inclinations? Of course not. And that is why, for much of the world, environmental strategy is what the middle classes worry about because they have been freed from the preoccupation with survival. (Immortality will be next on the agenda.)

The serious disappointment is what the white paper has to say, or has decided not to say, about strategic issues. If, at the most primitive level, environmental protection is about personal survival, the age-specific likelihood of death must be a useful index. So why not work out, using empirical as well as theoretical models, the chances that people will die or be incapacitated by this or that environmental insult? Is ubiquitous radioactivity more damaging than, say, ubiquitous PCBs? And by what factor? There is no compelling reason why a government should have an opinion on such an issue, but at least it might create a mechanism for resolving it. Apparently there is none.

Worse still, while This Common Inheritance glossily gives prominence to the problem of global warming, which may (or may not) be a consequence of the increasing concentration of carbon dioxide in the atmosphere, and while it properly acknowledges that the small chance of being wrong on such a huge issue could have consequences that would be calamitous, it does very little to help those who will read it to know where to put their money, or their energy and intelligence. Might it not have been politically as well as philosophically more prudent to have come to a decision and to have said that global warming is more (or less) important than clean streets, or one of the other 300 talismans of environmental probity in this policy-free policy statement?

Only against this background of lost opportunity does the white paper's strongest suit shine through, but the document is strong on the preservation of the appearance of the country over which the British government presides. Indeed, in that respect, even the philosophy makes sense - "the reason for keeping it like it is consists of people's inclinations", which is a kind of democratic principle. But in this connection, the white paper has very little to say about the anomalies of the British planning system (meant to prevent unpopular development), the associated economic issues (such as how a landowner prevented from development should be compensated, and by whom) and trivial but teasing questions such as how much effort should be spent in preserving British landscapes and appearances when they are replicated many times in the Europe to which Britain will soon belong. 